\title{
Del cuerpo guerrero al cuerpo deportivo: transformaciones culturales huaorani From warrior body to sports body: Huaorani cultural transformations
}

\author{
Angel Acuña Delgado \\ Universidad de Granada (España)
}

\begin{abstract}
Resumen. El objetivo principal de esta investigación centra la atención en observar cómo las transformaciones culturales experimentadas por los Huaorani (pueblo amerindio de la Amazonía ecuatoriana) en los últimos 60 años se reflejan en su corporeidad. En base a la metodología etnográfica aplicada, los resultados obtenidos llevan a analizar las implicaciones y consecuencias de tres modelos corporales: El cuerpo guerrero, hasta los primeros años del contacto en 1956, esencialmente instrumental para conseguir sustento y conservar la vida. El cuerpo cazador-recolector con el inicio del proceso «civilizador», que con las relaciones interculturales e interétnicas da origen a un cierto grado de transfiguración étnica. Y el cuerpo deportivo-expresivo, que, entre otras consideraciones, refleja la quiebra con la experiencia de sus mayores, conecta con los nuevos tiempos y posee una orientación especialmente relacional, recreativa, y comunicativa. Modelos corporales que ponen de relieve a su vez, la falta de diálogo y las distancias intergeneracionales.

Palabras clave. Huaorani, pueblos indígenas, cuerpo, persona, cambio cultural.
\end{abstract}

\begin{abstract}
The main objective of this research focuses on observing how cultural transformations experienced by the Huaorani (amerindian people of the Ecuadorian Amazon) in the last 60 years are reflected in their corporeality. Based on the ethnographic methodology applied, the obtained results lead to analyze the implications and consequences of three corporal models: warrior body, until the first years of contact in 1956, essentially instrumental to obtain sustenance and preserve life. Hunter-gatherer body, appeared with the beginning of the «civilizing» process, which with intercultural and inter-ethnic relations gives rise to a certain degree of ethnic transfiguration. And finally, sports-expressive body, which, among other considerations, reflects the rupture with the experience of its elders, connects with the current times and possesses a particularly relational, recreational, and communicative orientation. This body models highlight the lack of dialogue and intergenerational distances.
\end{abstract}

Keywords. Huaorani, indigenous people, body, person, cultural change.

\section{Introducción}

Esta investigación trata del cuerpo huaorani. Comenzaré por presentar la pertinencia del cuerpo como elemento de interpretación cultural, y a los Huaorani en su contexto histórico geográfico.

El cuerpo como vehículo de construcción e interpretación cultural constituye un tema de estudio ampliamente tratado en la literatura científica. Fue Protágoras, en el siglo V a.C., a quien se atribuye la célebre frase de: «el hombre es la medida de todas las cosas», y por inclusión lo mismo podríamos decir del cuerpo. Así lo daba a entender Merleau-Ponty $(1966,1985)$ al considerarlo como parámetro de todo complejo cultural. La relación cuerpo-mundo es indisociable. El cuerpo es el vehículo de ser en el mundo, y ocupa un papel esencial en el diseño de la realidad.

Mauss acuñó el término «técnicas del cuerpo», para poner de relieve las distintas «maneras que los hombres en cada sociedad, de un modo tradicional, saben servirse de su cuerpo» (Mauss, 1971, p. 345). Douglas (1978) impulsó su búsqueda de lo corporal hacia la relación existente entre la experiencia de lo físico y lo social. Csordas (1990) señala con su embodiment el papel existencial del cuerpo, al deber ser estudiado no como objeto sino como sujeto de la cultura. Velasco (2007) reafirma la superación del dualismo entre sujeto y objeto en la comprensión del embodiment (in-corporación). Dentro del sentido práctico del habitus (Bourdieu, 1980), como estructura estructurante, el cuerpo desempeña un papel crucial al generar y organizar las prácticas y las representaciones. Le Bretón (2002 [1990] destaca la realidad

Fecha recepción: 10-12-19. Fecha de aceptación: 22-02-20

Angel Acuña Delgado

acuna@ugr.es cambiante en el tiempo y el espacio del simbolismo corporal.

El cuerpo ha sido estudiado desde una perspectiva económica, como signo y mercancía, especialmente en la sociedad de consumo (Baudrillard, 1974; Bourdieu, 1978); desde una óptica comunicativa, como forma de lenguaje o sistema semiológico, productor de sentido (Birdwistell, 1952; Hall, 1972; Knapp, 1985; Goffman, 1987); y también como forma de control y de poder, desde una perspectiva política (Brohm, 1982; Foucault, 1984; Godelier, 1986; Esteban, 2004). La Educación Física lo ha contemplado igualmente como objeto de estudio (de la Torre et al, 2018; Arrayás, Torreo \& Díaz, 2018; Aguila \& López Vargas, 2019). El Congreso Internacional bianual denominado «El cuerpo descifrado», que en 2017 celebró su VIII edición, muestra a través de sus diferentes simposios la enorme cantidad de temáticas tratadas, en relación con la identidad, sexualidad, discriminación, salud, religión, estética, etc., algunos de ellos recogidos por Muñiz (2008) en su compendio sobre registros corporales.

Es en definitiva mucho el conocimiento científico acumulado en relación al cuerpo, entendido como receptor y contenedor de acontecimientos sociales y culturales, sujeto a significados diversos (Salinas, 1994). El esquema corporal o conciencia estimativa del cuerpo es preciso asumirla como un producto social, dado que la educación, ya sea formal o informal, tiende en cierta medida a modelarlo, a formarlo, a darle una determinada hechura de conformidad con las exigencias normativas de la sociedad en que se vive.

El cuerpo, por tanto, se convierte así en una excelente unidad de análisis en sí mismo, para comprender rasgos esenciales de la sociedad y cultura en la que está instalado. Para entender los procesos de cambio experimentados. Y, aunque cada grupo social posea sus propias técnicas corporales y su manera singular de dotarlas de contenido práctico y simbólico, cobra especial relevancia en pueblos estrechamente 


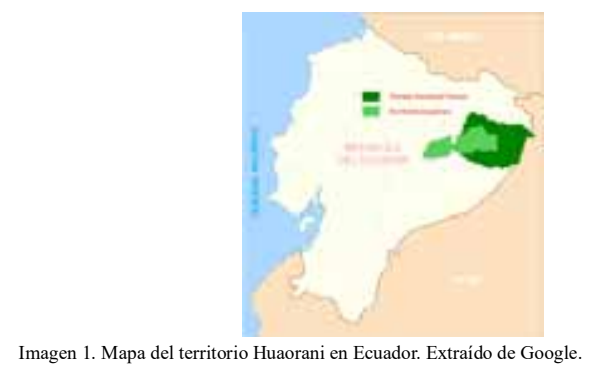

apegados a la naturaleza, con escaso desarrollo de satisfactores culturales de tipo artificial (tecnología industrial), que luchan por sobrevivir en su entorno, y tienen en el desarrollo de sus habilidades corporales las claves para lograr una existencia satisfactoria.

En lo que respecta a los sujetos de estudio, los Huaorani (o Waorani), conocidos también como Aucas, viven en la Amazonía ecuatoriana, entre los ríos Napo, al norte, y Curaray, al sur, y entre los meridianos $76^{\circ}$ oeste, $77^{\circ} 30^{\prime}$ este. (Imagen 1). Sobre el origen y el momento en que llegó este pueblo al territorio que ocupa, no existen datos arqueológicos ni históricos que lo permitan conocer con claridad (Yost, 1991; Cabodevilla, 1994).

En 1956 fueron contactados de manera infructuosa por el Instituto Lingüístico de Verano (ILV), a través de cuatro misioneros evangélicos que acabaron muriendo en el intento. Instituto que luego agrupó a la mayor parte de la población en un protectorado evangélico. Desde el principio, la política estatal llevada con ellos fue orientada en un doble sentido: «civilizar» e «integrar». La primera tarea se atribuyó principalmente el propio ILV; y la segunda fue delegada a las compañías petroleras, en una labor asistencialista para facilitar el desarrollo local, que generó un modelo de dominación y sometimiento, de relaciones asimétricas y pérdidas irreparables (Rivas \& Lara, 2001).

Del espacio físico ancestral donde se desenvolvían en épocas anteriores al contacto, estimado en unos dos millones de hectáreas, desde inicios de los años 90 a la actualidad les quedó 678.000 Ha., como territorio legalmente reconocido (Rivas \& Lara, 2001, p. 79).

El crecimiento demográfico es apreciable, teniendo en cuenta que la población estimada en 1958 fue de unas 500 personas (Yost, 1991) y en 2011 se estableció un censo de 3.265 (Zurita, 2017, p. 501). En la actualidad, las estimaciones escuchadas sobre el propio lugar los sitúan entre las $2.500 \mathrm{y}$ 3.000 personas, distribuidas en unas 50 comunidades de entre 10 y algo más de 200 habitantes. La Organización de la Nacionalidad Huaorani de la Amazonía Ecuatoriana (ONHAE) y laAsociación de Mujeres Waorani de la Amazonía Ecuatoriana (AMWAE), figuran como organizaciones representativas del pueblo.

En base al papel que desempeña el cuerpo en la construcción de la persona y en el diseño de la realidad, los objetivos centrales de esta investigación pretenden responder a dos preguntas claves: ¿cómo las transformaciones culturales experimentadas por los Huaorani en los últimos 60 años, se reflejan en su corporeidad? ¿qué implicaciones y consecuencias se desprenden de la corporeidad huaorani en las últimas generaciones?

\section{Metodología}

Invitado por la Universidad Central del Ecuador, el trabajo de campo etnográfico fue llevado a cabo desde el 14 de septiembre hasta el 17 de noviembre de 2018, en la comunidad de Toñampari ${ }^{1}$ circunscrita geográficamente en el cantón Arajuno, provincia de Pastaza, de la Amazonía ecuatoriana. Las técnicas empleadas para la producción de datos fueron: la observación sistemática de la vida cotidiana en la comunidad y de los escolares de la Unidad Educativa del Milenio existente en Toñampari, con registro en diario de campo; diario temático en el que las entradas cronológicas de datos fueron ordenadas en categorías analíticas, de acuerdo a los objetivos de la investigación; asimismo, los datos basados en hechos observados o escuchados (conversaciones informales incluidas) de manera objetiva, fueron complementados con reflexiones personales, distinguiendo con claridad el dato, de su interpretación subjetiva. Entrevistas semiestructuradas a 31 personas, hombres y mujeres significativas de diferentes edades entre 25 y 85 años, con la ayuda de traductor en 13 casos (para obtener los testimonios de piquenanis); interrogatorios formales todos ellos grabados con aparato digital y posteriormente transcritos para su análisis de contenido; las personas elegidas se ajustaron a determinados signos de distinción representativos dentro de la comunidad. Tres grupos de discusión en contexto escolar; junto con la elaboración de dibujos temáticos por parte del alumnado ${ }^{2}$; que nos permitió acceder al conocimiento de las actitudes y comportamientos de la población más joven; las reuniones fueron también grabadas en audio, y al igual que en los dibujos se realizó análisis de contenido. Los registros audiovisuales variados completaron por último el repertorio de técnicas metodológicas. Procedimientos que dieron en general excelentes resultados por la cantidad y calidad de datos obtenidos, gracias, eso sí, a una no menos excelente receptividad y colaboración de la población en su conjunto.

\section{Contexto etnográfico: Toñampari}

Situada junto al curso alto del río Curaray, la comunidad de Toñampari fue fundada en $1980^{3}$ con las personas o familias procedentes de Tiweno, el antiguo protectorado creado por el ILV. Las vías habituales de comunicación son los senderos y el propio río, por los que se camina o navega para llegar hasta las comunidades vecinas o salir a zonas de carretera y acceder al entorno urbano (Puyo o Tena); o bien la avioneta de la compañía Alas del Socorro que vuela desde la Shell.

La horticultura de la chacra ofrece variedad de cultivos, entre los que sobresale la yuca y el plátano con los que elaborar chicha y chucula, como productos esenciales de la dieta; a ello se une lo obtenido de la caza, pesca y recolección, que en conjunto constituyen los principales medios de vida $^{4}$. Debido a las dificultades de transporte, la actividad comercial se reduce a la venta de artesanías, elaboradas especialmente con cordelería por parte de las mujeres (hamacas, bolsos, recipientes, collares, pulseras), y madera por los hombres (cerbatanas, carcaj con dardos, lanzas, machetes, tallas variadas). 
El agua potable se canaliza por tuberías desde las quebradas próximas, siendo filtrada y almacenada por cada familia en depósitos independientes al uso. La luz artificial es producida por equipos electrógenos alimentados con combustible, aunque no todas las familias disponen de ellos. Y los residuos se depositan habitualmente en zanjas algo apartadas, que posteriormente se cubren de tierra una vez llenas.

De todas las comunidades huaorani, Toñampari es la más poblada, con un censo de 231 personas (120 hombres y 111 mujeres), repartidas en cuatro barriadas. No obstante, dada la movilidad e inestabilidad residencial de gran parte de sus habitantes, resulta difícil establecer un censo fijo, al igual que en el resto de comunidades. En la actualidad se trata de una comunidad esencialmente huao-quichua, en la que conviven 55 familias: 14 de padre y madre huaorani, siete con un solo progenitor o los dos quichua, y 34 con mezcla de huaorani y quichua.

La incorporación quichua al territorio huaorani ha introducido nuevos usos y costumbres (en la preparación de la chicha, la construcción de la vivienda, las relaciones familiares, etc.). Con ello lo huaorani ha perdido espacio, se ha fusionado con lo quichua en distintos aspectos, y reducido su poder por el prejuicio de superioridad que se le atribuye a lo quichua; sin embargo, no ha mermado el sentido de identidad indígena, que incluso en conjunto se puede observar fortalecido.

La modernidad ha incorporado notables cambios en la alimentación (con el consumo de sal, azúcar, arroz, pasta, conservas,...), el empleo de materiales de construcción (hormigón, hojas de zing, ...), de herramientas y aparatos electrodomésticos (motosierra, grupo electrógeno, cocina de gas, televisor, celular, ...). Especialmente se hace notar en las actitudes y expectativas de la gente joven; pero la economía de mercado no tiene un papel determinante, las transacciones producidas en el interior de la comunidad se basan en el principio de redistribución y reciprocidad, las abundantes mingas (reunión de amigos y vecinos para hacer algún trabajo en común) constituyen la expresión más generalizada de solidaridad interfamiliar, y la dependencia de dinero es mínima mientras no se salga al ámbito urbano. A excepción de quienes ejercen un empleo remunerado, básicamente en torno al Colegio del Milenio (profesores, vigilantes, limpiadores, cocinero), el resto de personas se mantienen con una economía de autosubsistencia. A diferencia de otras zonas, la negativa comunitaria a impedir que entren en su territorio compañías petroleras; y la ausencia de caminos carreteros por la que tengan acceso vehículos por tierra, hacen posible tal situación.

Los conflictos que afectan a la comunidad se resuelven en asamblea, presidida por uno de sus miembros, y en la que, al decir de algunos, la opinión de los piquenanis cuenta con mucho peso en la toma de decisiones. La costumbre ancestral de reclamar venganza y proclamar que la muerte se paga con muerte, aunque pueda estar presente aún en el imaginario de algunos y surja en situaciones extremas de ira, en el contexto de Toñampari se encuentra apaciguada, buscándose la justicia por otras vías.

Entre los agentes externos que han intervenido en la transformación socio-cultural huaorani, dentro del contexto de Toñampari, cabe mencionar: la política gubernamental (re- gional y nacional); el contacto con la sociedad mestiza; los medios de comunicación; la migración y mezcla con la población quichua; la empresa petrolera (indirectamente); la iglesia (evangélica); y la escuela. Todos ellos han provocado de uno u otro modo cambios significativos en las actitudes y comportamientos huaorani, aunque, por motivos de espacio y por su relevancia, solo comentaremos a continuación los dos últimos.

El denominado proceso de «civilización» huaorani, mucho tiene que ver con las iniciativas misioneras, y sobre todo con el papel desempeñado por la Iglesia Evangélica a través del ILV. En Toñampari y su entorno resulta significativo escuchar de algunos piquenanis que: «nosotros ya estamos civilizados, creemos en Dios y leemos la Biblia», al hacer comparación con los Tagaeri ${ }^{5}$ que aún no están en esa situación. Una mujer huao-quichua manifestaba: «nosotros ya civilizamos hace tiempo al conocer la Palabra de Dios, y saber lo que no se debe hacer, matar y eso» (C.A. 13/11/2018). La intensa labor evangélica, primero con el ILV y luego con las distintas iglesias que han aparecido por aquí, ha calado bien hondo en la población a la vista de los resultados: en el culto de los domingos, oficiado generalmente por pastores huaorani en formación, la iglesia o templo se llena de gente realmente convertida, como observamos por los gestos y las palabras que se expresan, también y de modo destacado por los propios piquenanis que sirven de modelo.

Las creencias antiguas sobre la muerte están ya en el olvido, ahora se imponen las creencias que trajeron y siguen trayendo los misioneros. Todos los domingos se reúnen y hablan de la Biblia. (R. N. Nombre huaorani. Vicerrector de la Unidad Educativa del Milenio. 29/09/2018).

Con los misioneros yo he aprendido que había que cambiar las costumbres de matar para vengarse, ya había que parar y vivir en paz. (A. Hombre piquenani. Traductor A. Gaba. 11/11/2018).

Antes, cuando morían se convertían en tigres (jaguar), ahora ya con la misión se piensa de otra manera. (W. B. Mujer piquenani. Traductor O. Yeti. 22/10/2018).

La idea del pecado está ahora presente y, en consecuencia, la penitencia que hay que aplicar cuando se comete o la conducta no es cristiana. Del miedo en la vida presente por la amenaza de enemigos que matan por venganza, se ha pasado al miedo en la vida futura por la amenaza del infierno y el demonio que espera a los infieles.

En la tradición, la buena muerte era la del guerrero en la batalla, cuando ocurre en defensa propia o en el ataque, aunque no de manera traicionera. La mala muerte era la producida por chamanismo. En la actualidad, sin embargo, la mala muerte es la que se produce por motivos violentos, bien sea homicidio o suicidio; mientras que la buena muerte es la que se produce en paz con Dios, con el arrepentimiento de las malas acciones o pecados.

Un destacado piquenani de unos 85 años, único superviviente (en noviembre de 2018) que participó en la matanza de los cinco misioneros evangélicos en 1956, actualmente oficia el culto como pastor en Tzapino, comunidad de 32 habitantes, próxima a Toñampari, donde reside. Reflexionando sobre su pasado y su futuro, manifestaba:

Ya dejé la lanza a un lado, ya no asesinamos. No sabíamos quiénes eran los misioneros, [...] ahora nos enseñan la 
Biblia y a amarnos unos a otros, todos somos hermanos y no podemos seguir con las venganzas. [...] cuando vuelva Dios quiero ir al cielo por haber creído en él. (M. Hombre piquenani. Traductor O. Yeti. 23/10/2018).

Aunque hay todavía alguno que, como nos contaba, el culto le apacigua el ánimo por momentos, pero añora tiempos pasados, y hay situaciones en las que está tentado de escarmentar a alguien a la antigua usanza.

Ahora estoy tranquilo porque me predican la Biblia y tengo hijos, si no, me hubiera ido a matar. (T. C. Hombre piquenani. Traductor O. Yeti. 22/10/2018).

La Misión Ecuador para Cristo, de implantación nacional, opera en el área de Toñampari desde hace años con un programa llamado Compasión Internacional, por el que niños y niñas son apadrinados por personas o familias de distintos países, que les hacen llegar regalos: juguetes, útiles escolares, golosinas, apoyándolos en el periodo de formación. En sus tres o cuatro estancias anuales de una a dos semanas en la comunidad, realizan jornadas intensivas con jóvenes y adultos, para promover y afianzar la palabra de Dios, así como para formar a algunos, hombres y mujeres, en la responsabilidad de hacer catequesis con los pequeños y oficiar el propio culto. En Toñampari el culto dominical es oficiado por A. Gaba, y en su defecto por sus hermanos W. Gaba o F. Gaba, todos ellos en formación. También participa activamente con sus sermones el piquenani Amoa. Dentro del templo, al pie del altar, se lee: «Wapunini itota wadekampa tomayo imunye iñomo», que se traduce como: Dios ama a todos aquí.

Otro gran agente transformador ha sido y es el sistema educativo, que en Toñampari, tras cinco años de construcción, cuenta con una institución especial, inaugurada el 26 de enero de 2017: la Unidad Educativa del Milenio. Centro de enseñanza con capacidad para 500 estudiantes, cuenta con aulario, laboratorios, área administrativa, áreas deportivas e internado para 150 personas. Moderno e impactante recinto dirigido de manera esforzada y comprometida, pero con serias carencias de personal (profesorado y administración insuficiente) y mantenimiento (deficiencias en servicio de agua, falta de energía eléctrica, de acceso a internet, etc.) Dentro de las propias instalaciones se encuentra también el Centro de Salud de nivel 1, donde se prestan servicios de atención primaria (medicina, vacunación, enfermería, odontología), y en donde trabajan tres médicos, un odontólogo y dos enfermeros, por turnos. Además de la atención permanente en Toñampari, realizan brigadas médicas con salidas a 10 comunidades cercanas.

El sistema educativo es sin duda un importante agente de transformación, por los conocimientos que las nuevas generaciones aprenden y esperan aplicar en el futuro. La malla curricular impartida en Toñampari a los diferentes niveles de docencia (10 niveles de Enseñanza General Básica y 3 de Bachillerato) es semejante a lo que se recibe en el resto del país. En tal sentido y dado el carácter de la población, se echa en falta una enseñanza bilingüe e intercultural adecuada. Las materias se imparten en castellano y no existe adaptación alguna a la idiosincrasia del alumnado, el cual desconoce, entre otras cosas, la historia de su pueblo. Una imagen significativa del interés existente por poner en valor el conocimiento de la historia y la cultura huaorani la encontramos en la Biblioteca, que con 18 hileras de estanterías de libros, nuevos en su mayoría, la temática indígena se limita a una decena de textos viejos, mal seleccionados, al tratarse de «Indios de las Antillas», «de Canadá», «de Uruguay»; todos ellos colocados en la parte baja del último estante y contra la pared, el lugar más marginal. Se abren buenas expectativas, no obstante, con la reciente creación de la Escuela Intergeneracional, por iniciativa de la Universidad Central del Ecuador, para facilitar el diálogo entre jóvenes y mayores, así como la recuperación de los usos y costumbres huaorani; Escuela de la que se hará cargo la Unidad Educativa del Milenio, cubriendo así la laguna que posee en ese sentido. Reto importante a conseguir, del que está por ver el funcionamiento y resultados futuros.

En 2018 se hallaban 150 alumnos matriculados: 85 varones $(56.7 \%)$ y 65 mujeres (43.3\%); 42 de ellos internos. Un tercio aproximadamente de su capacidad. Pero a un año escaso de su estreno, las enormes disfunciones observadas ${ }^{6}$ hacen pensar en la deficiente planificación y gestión de los recursos por parte del Estado, lo cual no es ninguna novedad por la mucha crítica vertida en la literatura sobre otras Unidades Educativas del Milenio construidas en el Oriente ecuatoriano, caso de Cuyabeno, Pañacocha o Nuevo Rocafuerte en la cuenca del Napo (Goldáraz, 2017; Wilson \& Bayón, 2017)

La materia que más cuesta asimilar al alumnado es Lengua y Literatura, $\mathrm{y}$, aunque en la comunidad y en la casa el $100 \%$ habla huao terero, los jóvenes tienen dificultad para escribir en huao, al no estar habituados. También el quichua es hablado por la mayoría. En huao terero se imparte una sola asignatura en bachiller, aunque lo que todo el equipo directivo reconoce que falta es interculturalidad. El inglés también está previsto potenciarlo, con vistas a continuar estudios universitarios, pero precisamente uno de los docentes que faltan es el de esta materia.

Entre los reproches más comunes del profesorado sobre el comportamiento del alumnado destacan la excesiva atención prestada a los celulares (teléfonos móviles), que muchos de ellos tienen; y la indisciplina de algunos, atribuible a un mal ejemplo familiar.

La atención a los celulares hace que pierdan el interés por la pesca. La gente dedica mucho tiempo con los celulares y es perjudicial. (R. N. Huaorani. Vicerrector de la U. E, del Milenio. 29/09/2018).

En la rebeldía de los jóvenes también interviene la falta de responsabilidad de los padres, que no corrigen a los hijos, lo dejan todo a nosotros y se desentienden. Hablamos con ellos, hacemos talleres con los padres y resultó positivo para que sepan el rol de cada uno y se sepa aplicar. La educación debe partir del hogar. (L. C. Quichua. Rector de la U.E, del Milenio. 29/09/2018).

A pesar de todo, el Rector, que junto al Vicerrector, suben con frecuencia en la noche a un cerro cercano (El Mirador) donde hay señal de internet, para enviar informes al Ministerio de Educación, produciendo así una imagen que pareciera un espejismo, piensa así:

Mi valoración en cuanto al funcionamiento es que está a un 70\%, la docencia, las matrículas, la política educativa, es la apreciación que tenemos como docente, padre y miembro de la comunidad. Ahora tenemos los medios que hay en la 
ciudad pero falta ponerlos a funcionar realmente para sacarles rendimiento. (L. C. Rector de la U.E. del Milenio. 27/09/ 2018)

Positiva, es en general la opinión de la población, que además de haber tenido ocasión de trabajar durante casi cinco años en su construcción, con la entrada de ingresos económicos que supuso ${ }^{7}$, lo ven ahora como una oportunidad para el desarrollo dentro de la selva donde viven, en semejantes condiciones a las que existen en la ciudad.

La Escuela del Milenio está muy bien, es moderna y los chicos disfrutan de sus instalaciones, y es agradable verla aquí en medio de la selva. (D. Mujer huaorani. 13/11/2018).

Ingenua o no la opinión, lo cierto es que el nuevo colegio desempeña un papel especial para la comunidad, resultando llamativo escuchar decir a algunas personas, cuando desde sus barrios se dirigen al Milenio: «voy al otro lado». No es la otra orilla del río Curaray, sino el lado simbólico de la modernidad, un espacio diferencial. Ya hace más de 20 años, Laura Rival expresaba que la escuela es «el lugar donde se pone en práctica la conducta civilizada.» (Rival, 1996, p. 312).

\section{Análisis y discusión de resultados}

A la vista de las profundas transformaciones experimentadas por los Huaorani en sus últimos 60 años, debido a la influencia ejercida por los distintos agentes con quienes han entrado en contacto, vamos a ver a continuación cómo tales transformaciones en las maneras de ser y estar en el mundo se pueden observar a través de su corporeidad, cómo la percepción y representación del cuerpo reflejan adaptaciones a expectativas diferentes con el paso de los años, y cómo al mismo tiempo, los cuerpos generan maneras distintas de afrontar los desafíos que en cada momento impone la vida. Teniendo en cuenta que el cuerpo, como estructura cultural, funciona como un modelo de comportamiento y un modelo para producir o desarrollar comportamientos (Geertz, 1987[1973].

Desde el inicio del contacto en 1956 a la actualidad, han transcurrido hasta cinco generaciones, contándose aún con representantes de la más antigua: piquenanis de más de 80 años (con más de 20 en 1956); piquenanis de 60 a 70 años (que eran niños en 1956); hijos de estos últimos piquenanis, de 20 a 50 años; nietos o bizbienos de piquenanis, de hasta 20 años aproximadamente; y por último, biznietos o tataranietos de piquenanis, con pocos años de vida. Cada uno de ellos, incluidos los de edades intermedias a las citadas, cuenta con una biografía diferencial que ha hecho huella en sus cuerpos; no obstante, con fines analíticos, observaremos tres tipos de corporalidad que distinguiremos como: guerrera y cazadora-recolectora (primera generación), cazadora-recolectora (segunda y tercera generación) y deportiva-expresiva (cuarta y quinta generación).

\section{Cuerpo guerrero}

Los valores tradicionales de los antiguos estaban en sintonía con el estilo de vida guerrero y cazador-recolector, por lo que ser valiente, aguerrido, duro, fuerte, resistente, indolente, disciplinado, trabajador, solidario con los suyos, vengativo con los enemigos, eran atributos destacados del hombre y de la mujer, cada cual en su papel.
En base a los trabajos de Robarchek \& Robarchek (1998), Rival (2015, p. 20) señala que los Huaorani tienen «la más alta tasa de homicidio de cualquier sociedad conocida por la antropología». Matar seres humanos formaba parte de su modus vivendi, de su ethos, especialmente varonil. Y son las matanzas y acciones guerreras, los hechos más singulares que han marcado a los ahora piquenanis, que en el pasado pudieron ejecutarlas o presenciarlas y escapar a ellas.

En las matanzas se mataba primero al menor de los hermanos y luego al mayor, que era menos problemático [...] Los dos (Moipa e Iteca) iban a una casa a preguntar, brindaban con chicha y luego mataban a todos para evitar venganzas. [...] Cuando tenía 11 años llegaron tres guerreros: Quinta, Owe y Amira, y los mataron por problemas de matrimonio, entonces se dividieron las familias. (E. Mujer piquenani de Toñampari. Traductor F. Gaba.13/10/2018).

Había un guerrero llamado Neñime que iba matando colonos y quichuas y su familia se apartó de él para evitar que los matara. [...] También cuando la gente zápara se encontraba dentro de su casa y llovía mucho, con truenos fuertes, comiendo mono dentro, no se daban cuenta y ahí mataban (Moipa e Iteca) a toditos con lanza. (C. Hombre piquenani de Toñampari. Traductor F. Gaba. 15/10/2018).

Algunos piquenanis de mayor edad, tuvieron la experiencia de matar en su juventud, al protagonizar ellos mismos matanzas, como cuentan:

Solo para conseguir hacha y machete íbamos a los campamentos a matar gente. [...] Kento estaba escondido, [...] la mujer me dijo que él es el asesino de mi padre, por eso lo estoy matando. (M. Antiguo guerrero, piquenani de Tzapino. 23/10/2018).

Había que acostumbrarse a las matanzas. [...] Maté a la madrastra que me crio porque ellos mataron a mis padres. ( $T$. Antiguo guerrero, piquenani de Kiwaro. 22/10/2018).

Las mujeres participaban también a su modo en las acciones guerreras:

A Namo lo lancearon en la espalda, estaba solo, luego las mujeres lo rodearon y lo mataron con machete. A una de tanto cortar se le rompió el machete. [...] también era guerrera, tenía una espada tipo machete llamado campa, que daba en rodilla, costado, cuello, para atacar a los guerreros y defenderse. (K. Antiguo guerrero, piquenani de Tzapino. 23/ 10/2018).

Resultan muy llamativos los testimonios de quienes siendo niños o jóvenes, debían huir al bosque o buscar protección en alguna maloca (vivienda), cuando sus propios familiares llegaban furiosos tras una incursión guerrera o se hallaban muy malhumorados. La ira era peligrosa siempre porque se aplacaba matando, y con frecuencia no respetaba lazos de parentesco.

Como forma de adiestramiento para conseguir ser buen guerrero y abastecedor/a de alimentos, los niños y niñas recibían severas lecciones de los mayores: ellos eran azotados en brazos y piernas con bejuco y ellas con ortiga, a veces también eran untados sus párpados con ají; unas veces se hacía para castigar algún comportamiento inadecuado y evitar así la vagancia, el descuido o la torpeza; y otras sencillamente para curtir el cuerpo en el sufrimiento físico y soportar el dolor. Los jóvenes practicaban haciendo lanzas con palo de balsa para no dañar en los ensayos de lucha. Y 
en las celebraciones festivas los valerosos guerreros refregaban a los menores por sus cuerpos sudorosos durante las danzas para que se impregnen y adquieran sus virtudes. Así lo recuerdan algunos/as:

Mi papá era guerrero y me decía que tenía que ser fuerte como él, obedecer lo que él dice y estar preparado para matar, si hace falta hacerlo. [...] mi papá me castigaba con bejuco especial para que creciera fuerte. (D. Hombre piquenani de Kenaweno. Traductor G. Guiquita. 16/10/2018).

Cuando era niña me obligaban a despertar temprano para que fuera obediente y trabajadora, si no levantaba me echaban agua en la cara. [...] Cuando los cazadores traían animales a los niños le daban con bejuco y a las niñas con ortiga para que fuéramos como ellos. (T. Mujer piquenani de Kiwaro. Traductor O. Yeti. 11/10/2018).

Antes se daba la sabiduría a través del castigo y así conseguía el poder para vivir en la selva sin quejarse de nada, corriendo, subiendo árbol, tumbando árboles. Con hacha de piedra tenían que tumbar cinco árboles y si no lo hacían recibían castigo. (C. Hombre piquenani de Toñampari. Traductor F. Gaba. 14/10/2018).

Las cicatrices que dejaban las heridas eran las marcas de los cuerpos guerreros, a lo que se sumaban otras marcas de accidentes fortuitos en la selva. Pero de manera deliberada a los huaorani de ambos sexos al inicio de la adolescencia, que venía a coincidir con la primera menstruación en las niñas y con la aparición del vello púbico en los niños, se les perforaba los lóbulos de las orejas con una espina de chonta, para introducir en ellos cilindros de madera de balsa cada vez mayores para agrandarlos progresivamente (Imagen 2). Según Rival (1996) era un signo distintivo de su identidad étnica, aunque los propios piquenanis dan versiones diversas. De manera opcional y menos frecuente se perforaban también el tabique nasal colocando una pluma atravesada, contaba Wima, mujer piquenani, y las mujeres se adornaban para estar bonitas.

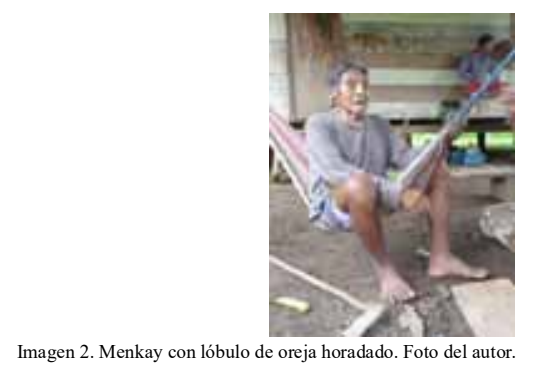

El arete en la oreja también se hacía como castigo. [...] cada vez que mostraran vagancia (chicos y chicas), le hacían más grande el orificio. [...] El hueco en la nariz era opción de cada uno y ponían pluma de ave diferente para distinguirse. [...] Para gustar a los hombres la mujer se pintaba el cuerpo, se perfumaba con plantas aromáticas y ponía corona. (W. Mujer piquenani de Kiwaro. Traductor O. Yeti. 22/10/2018).

Tras la muerte, los cadáveres eran enterrados en un agujero cavado en vertical, con el cuerpo ligeramente inclinado $\mathrm{y}$ agrupado, de manera sencilla y rápida, sin mayores atenciones, en el convencimiento de que serviría de alimento a la tierra, los animales y plantas del lugar. El espíritu ${ }^{8}$ por su parte viajaría al nanicabo (el mundo de los muertos) y se transformaría en jaguar, el dominador de la selva. Amoa, piquenani de Toñampari, contaba cómo al morir su papa, su mamá le dijo que vendría convertido en tigre (jaguar). Algunos cuerpos yacían sobre el mismo sitio donde hallaron la muerte, para ser comidos por el águila arpía, el cóndor o las tortugas, al no contar con familiares o allegados que los pudieran enterrar, caso de matanzas a familias completas o comunidades arrasadas. Y no son pocos los casos narrados en que la persona fallecida era acompañada por alguna otra, enterrada viva para que la acompañara al más allá.

Algunos bebés se enterraban vivos con su papá muerto, el hijo más querido. En Kiwaro había una abuelita que era medio chamán y cuando murió su nieto, el padre empujó a la abuela al hoyo para ser enterrada con su nieto, aunque estuviera viva y allí murió. (E. Mujer piquenani de Toñampari. Traductor F. Gaba.13/10/2018).

Pese a la permanente incertidumbre, estado de alerta y peligro de muerte que imponía el estilo de vida antiguo, resulta interesante observar la sonrisa que acompaña a buena parte de los piquenanis y adultos, así como la que se aprecia en sus expresiones a través de fotografías antiguas. Haber experimentado acontecimientos de violencia extrema en sus vidas, no parece que generara actitudes depresivas y rostros tristes, más bien, el hecho frecuente de sonreir mientras se conversa, denota la alegría de vivir, o tal vez de continuar vivo.

\section{Cuerpo cazador-recolector}

Una segunda categoría corporal la encontramos en los piquenanis más jóvenes de ahora, que, aunque contemplaron las matanzas no llegaron jamás a ser guerreros en el pasado, y junto con sus hijos, mantuvieron la tradición de cazador-recolector. Con el contacto y la labor misionera, la costumbre guerrera fue desapareciendo para instalarse el respeto al prójimo. El aleccionamiento en el cristianismo y el conocimiento del sistema judicial nacional, no impidió, sin embargo, que la lógica de la venganza siguiera presente, y la muerte se continuara pagando con muerte en ocasiones, algunas muy sonadas y difundidas por los medios de comunicación, como la matanza de los Tagaeri y Taromenani en 2003 y 2013 (Cabodevilla \& Aguirre, 2013).

En este modelo, los cuerpos huaorani siguen siendo cuerpos duros y resistentes, acostumbrados a la vida en la selva, cuerpos capaces de desplazarse con agilidad y rapidez en la frondosidad vegetal, y cubrir enormes distancias cargando peso. El respetado y admirado piquenani Amoa de unos 65 años, sigue yendo a cazar a lugares lejanos, camina durante ocho o diez horas y vuelve siempre con una huangana, un venado, monos, pavas, u otros animales, cargando más de $40 \mathrm{~kg}$. A falta ya de incursiones guerreras regulares, el huorani ha de continuar mostrando su capacidad de aguante. Cuando se interna en la maleza para cazar, sube a un árbol espinoso, o camina sin descanso, no ha de lamentarse por las picaduras, rozaduras, heridas en la piel o cansancio, ha de estar siempre preparado y afrontar cualquier desafío físico con entereza y decisión. Lo importante es conseguir el objetivo, lo que cueste lograrlo es lo de menos. Para ello la actitud mental es crucial y ha de estar instalada en la idea de: no hay dolor. Así describía un huaorani de unos 35 años lo que veía en su padre ocupado en tarea de recolección:

[...] (mi papá) era un hombre fuerte y resistente que llegó a vivir aquí. [...] Yo soy el hijo mayor. [...] para subir a la 
chonta (árbol espinoso), antes se pinchaba él mismo por los brazos, las piernas, y luego subía a coger chontaduro. (F. G. Huaorani de Toñampari. 03/10/2018).

El carácter indolente no evita, sin embargo, que los cuerpos sean cuidados para mantener su buen estado. Los piquenanis afirman que antes los huaorani, además de ser más fuertes y resistentes que ahora, apenas enfermaban, y cuando lo hacían tenían efectivos remedios a los que acudir, el ajo de monte era una especie de genérico de lo más utilizado, pero además cuentan con recursos específicos para mordedura de serpiente, problemas del riñón, del estómago, para quitar verrugas, provocar infertilidad en las mujeres, aumentar la potencia sexual, etc. Uno de los aspectos que más sorprenden al día de hoy, es comprobar el extraordinario conocimiento que los mayores y parte de los adultos tienen de las propiedades medicinales de las plantas, así como del entorno natural en general. Conocimiento que aplican a su bienestar. Hombres y mujeres se arrancan su vello facial y púbico, y usan similares diseños de pintura corporal (Álvarez, 2011, p. 209). De acuerdo con Rival (1996), los huaorani procuran vivir su corporeidad placenteramente y evitan las molestias corporales cuando se producen, lo cual no deja de ser compatible con su indolencia en la consecución de objetivos.

Otro rasgo apreciable en la corporeidad cazadora-recolectora es la autosuficiencia o autonomía personal en la que se instruyen, como forma de supervivencia en un entorno repleto de fuerzas depredadoras que amenazan de distintos modos. De acuerdo con Rival (2015, p. 286): «los niños huaoranis aprenden desde edad muy temprana que la gente real (los únicos verdaderos seres humanos) deben tener el control de sí mismos y que uno tiene que saber cómo sobrevivir sin necesidad de nadie más». Los bebés mantienen un contacto estrecho con la madre hasta que comienzan a caminar, en los primeros pasos también se atiende de cerca sus necesidades, pero a poco que comienza a tener autonomía se le deja cada vez más solo para que resuelva sus necesidades por sí mismo, haciéndolo de ese modo independiente desde temprana edad. Resulta significativa la poca atención prestada hacia las dificultades que pudiera tener mi persona cuando los acompañaba en largas travesías o incursiones de caza: al pasar obstáculos, puentes de árboles suspendidos a gran altura, zonas fangosas, etc., ni miraban atrás, el de cabeza establecía un ritmo y había que seguirlo, en la convicción de que cada cual es responsable de lo que hace y ha de saber cuidar de sí mismo.

Independencia personal que se complementa con la idea de compartir una esencia física común. El hecho de comer los mismos alimentos, compartirlos, dormir bajo el mismo techo y vivir juntos, genera fuertes lazos y sentimiento de unidad. Independientes, pero partícipes de una sustancia común. Los buenos modales exige un ejercicio de reciprocidad por el que cada cual ha de repartir lo que tenga y pueda: carne de caza, pescado, piñas, guanábanas, etc. Cuerpos por tanto solidarios y generosos, alejados de la mezquindad, y dispuestos al sacrificio, a sufrir escasez, si es preciso, por el beneficio mutuo. En expresión de Rival (2015, p. 241): «son ferozmente igualitarios y orientados al presente».

Por otro lado, los hijos de piquenanis experimentaron ya el mestizaje físico de manera acusada, como se puede apreciar por el elevado número de familias huao-quichuas exis- tente en Toñampari. De la fórmula tradicional de matrimonio, en la que los padres por mutuo acuerdo asignan y establecen las parejas de sus hijos, se empieza a aceptar que sean los hijos quienes las elijan; y así, por la cercanía y la interacción con otros pueblos, especialmente quichua, los cuerpos estrechan sus lazos y comienzan a producir otros cuerpos en los que las distinciones étnicas se fusionan. La resistencia al mestizaje que apuntaba Rival (2015, p. 23), y que caracterizaba a los primeros huaorani tras el contacto, se ha ido evaporando por el devenir de los acontecimientos.

Fruto de ese mestizaje, usos y costumbres se entrecruzan y aparecen nuevos comportamientos en los que se aprecia el predominio de uno de los grupos. Los cuerpos huaorani son los que mejor se desenvuelven en la selva, los más poderosos en ese sentido; pero la idea de atraso y primitivismo que evocan, hace que se impongan las propuestas de otros cuerpos, menos adaptados al entorno, pero más asociados a la idea de progreso y modernidad. La construcción de la vivienda, el tipo de vestuario, el uso de la cama para dormir, la preparación de alimentos, etc. son ya en buena medida prácticas importadas; pero, junto a la satisfacción con muchas de ellas, encontramos no pocas críticas a comportamientos inadecuados que antes no existían, tales como el consumo de alcohol, el maltrato físico a la esposa, la violación, o el suicidio; en general, nuevas formas de violencia hasta hace poco desconocidas para el grupo.

Desde que los huaorani se casan y se mezclan con gente quichua, ahí los jóvenes empezaron a tomar alcohol y a venir los problemas, a tomar barbasco, en vez de vivir bien, se mueren. [...] Antes no les pegaban a las mujeres y ahora los esposos toman alcohol, le jalan del pelo, les pegan, [...] (M. Guerrero piquenani de Tzapino. Traductor O. Yeti. 23/10/ 2018).

\section{Cuerpo deportivo-expresivo}

Si bien los hijos de piquenanis constituyen una generación situada entre la transmisión del conocimiento tradicional de sus mayores, y la adquisición de conocimientos venidos de fuera; los nietos, biznietos y tataranietos constituyen en conjunto una generación (hasta los 30 años aproximadamente) poco interesada por el pasado de su pueblo, y muy atenta a lo que le depara los tiempos modernos. El cuerpo, de nuevo, como receptor o contenedor de todo lo que ocurre a su alrededor, cobra ahora un carácter deportivo y expresivo para proyectar las nuevas inquietudes y tendencias.

En la actualidad los valores de la juventud resultan algo confusos, dado que no asumen lo que les trasmiten los mayores, ni tampoco tienen del todo claro lo que les ofrece la vida moderna; entre tanta oferta, tantos estímulos, surge la confusión. No obstante, en consonancia con los nuevos tiempos, los valores se dispersan, son más heterogéneos que antes y cada cual elige aquello por lo que más motivado se encuentra. Las formas de realización personal ofrecen opciones diversas.

El deporte, sin embargo, constituye una opción de la que todos participan en mayor o menor grado, en especial la práctica del fútbol y del voleybol a tres ecuatoriano, en menor medida el baloncesto. Chicos y chicas indistintamente se encuentran por la tarde en las pistas deportivas del Milenio, o en el Coliseo, pabellón polideportivo con gradas y a cu- 
bierto del antiguo recinto escolar, para hacer equipos mixtos y echar partidos. Los fines de semana con la participación también de adultos e incluso algunos piquenanis. Un joven huao-quichua decía que su abuela Tamaya jugaba antes al fútbol en el Coliseo, mejor que muchos. Competiciones deportivas en las que predomina el componente lúdico por encima del agonístico. Se trata de pasar un rato divertido, demostrando las habilidades que cada cual tiene con el balón, pero, aunque todos se afanen por ganar, no es el resultado lo más importante ${ }^{9}$. Los equipos de fútbol con frecuencia están desequilibrados en número de jugadores, no se hacen entradas duras, la violencia está ausente, y la risa o los comentarios jocosos son una constante en el transcurso de los partidos, sobre todo cuando alguien falla o cae al suelo. Sirve así para compartir con los demás y desprenderse de inhibiciones. La actividad deportiva facilita el desarrollo corporal y el encuentro social, no solo intracomunitario, también extracomunitario cuando por motivos de fiestas o trofeos, se organiza campeonatos entre comunidades. Al igual que proporciona motivos de conversación y conexión con el mundo global por las adhesiones escuchadas a Leonel Messi o a Cristiano Ronaldo.

Cuerpo que desarrolla las habilidades y destrezas que exige cada juego deportivo, algunos con un excelente nivel técnico y de performance, pero carentes de las capacidades que tenían los mayores. De los antiguos piquenanis se cuentan hazañas de enorme exigencia física, y de los actuales y sus hijos, hechos tales como por ejemplo: caminar durante seis o más horas cargando a la espalda un tanque de gas (20 kg.), más un quintal de arroz ( $50 \mathrm{~kg})$, más el niño pequeño de tres o cuatro años $(15 \mathrm{~kg}$.), desde la carretera del Tena a Damoentaro. O cómo transportaban sacos de arena de $50 \mathrm{~kg}$ sin descanso durante todo el día, día tras día, contratados por la compañía Cantarida en la obra del Milenio. Esfuerzos que la juventud de ahora es incapaz de realizar por falta de adaptación.

Los más jóvenes han perdido en su mayoría las habilidades de cazador-recolector de sus padres, pero esos padres también practican los deportes de sus hijos, mostrando un cuerpo mixto en destrezas que podríamos denominar $<<$ cazaportivo $>>$. Una imagen significativa de tal circunstancia la encontramos al caminar con algún que otro adulto, que al acompañarlos en la cacería, con machete, lanza o fusil en mano, visten con la equipación deportiva y el número de jugador a la espalda de la camiseta (Imagen 3).

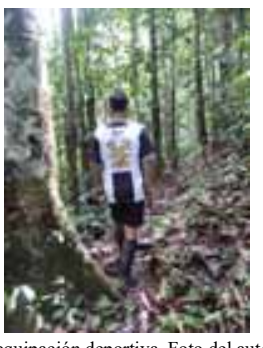

Imagen 3. O. Yeti, cazador con equipación deportiva. Foto del autor.

Es en el colegio donde se aprenden las disciplinas deportivas, así como juegos de manual empleados en el ámbito urbano, sin embargo, todavía se pueden observar en el contexto extraescolar niños y niñas jugando al pilla pilla encima de un árbol, moviéndose por las ramas con gran agilidad para evitar ser tocado por el perseguidor. Algunos adultos, no obstante, como F. Gaba y R. Nihua, critican que en las clases de Educación Física se dediquen a jugar a «patito patito», que resulta ridículo, y no se enseñe a tirar con lanza, lanzar dardos con bodoquera, subir a los árboles, a nadar o a bucear en el río.

Si bien los jóvenes se muestran en general desconsiderados con los valores tradicionales de sus mayores; los adultos y especialmente los piquenanis reprochan a los jóvenes, no solo que no sigan su ejemplo, sino que copien la conducta de los cowodi (extranjeros depredadores, antes tenidos por caníbales). Estos ven en ellos unos cuerpos débiles, poco hechos al trabajo y la vida en selva. Amoa, Coba, Come o Kemo, todos ellos piqueanis de Toñampari y su entorno próximo, hablan de los cuerpo pequeños y débiles de los jóvenes, semejante al de los runas (quíchuas), en comparación con la dureza, el vigor y la fortaleza de sus propios cuerpos y el de sus antepasados, circunstancia que atribuyen a la mala alimentación, al alcohol y a la falta de costumbre.

El cuerpo deportivo de los jóvenes no cuenta con las cicatrices de los guerreros o cazadores, pero sí inscriben en su piel huellas de su tiempo. La tendencia a imitar lo novedoso que viene de fuera hace que los tatuajes cobren presencia. Chicos y chicas, también algunos adultos, inscriben en su piel, especialmente de brazos y piernas, torso, espalda, dorso de mano y cuello ${ }^{10}$, diversos motivos: nombres de personas, rostros, animales, palabras sacadas del evangelio, emblema militar, cruces, estrellas, líneas sinuosas, figuras variadas, el número de cédula, etc.; muchos de ellos sin significado especial, la intención es lograr una segunda piel o piel social (Velasco, 2007, p. 71), como tienen otros, sin que el mensaje inscrito tenga mayor importancia. Símbolos, en cualquier caso, grabados por ellos mismos de unos a otros con tinta china de manera poco profesional, que sintoniza con el lenguaje de una nueva época, en la que los jóvenes disponen libremente de sus cuerpos e inscriben en él lo que estiman oportuno, ya que es de su propiedad, sin que los padres ni nadie se inmiscuyan. También el piercing se hace notar en algunos, con horadaciones en el ombligo, la nariz, el labio o la oreja, e incrustación de un aro u otra forma metálica. Una nueva estética acompaña el cuerpo deportivo, con peinados a la moda, al igual que el vestuario, si se puede conseguir, y olor a jabón, olor que, al decir de Epee, mujer piquenani, no soportan los Tagaeri, ni los Huaorani de antes. La exaltación de la belleza física forma parte de las preocupaciones de los jóvenes para gustar a los demás y conseguir pareja: las chicas depilan sus cejas, pintan sus labios, sus uñas; y los chicos se musculan y acicalan a su manera, conscientes de que el éxito pasa por la mutua atracción.

Con motivo de la Fiesta anual en Toñampari a mediados de enero de 2019, un grupo numeroso de voluntarios del colegio se comprometió con la comunidad en presentar para esos días una exhibición de baile. Algunas mujeres adultas sugirieron que fuera el baile tradicional huaorani, y también otros bailes o danzas que podrían ser quichua o shuar. El grupo de baile, haciendo oídos sordos a tales sugerencias, dedicaba los ensayos a bailar bachaca y reguetón, que era lo que decidieron presentar. Bailes modernos que les resultaban más atractivos. El hecho es significativo de los gustos y 
tendencias de los jóvenes y de cómo van a ir construyendo el futuro. En cuestión de ritmos musicales, lo tradicional no les estimula, no les resulta significativo, y, si no es por imposición de los mayores, las elecciones que adopten se harán de acuerdo a lo que ellos decidan. Al igual que los gestos de artes marciales en los chicos, que a veces observaba, o la elección de Reina de la Fiesta cada año, son todos ellos esquemas copiados del exterior por los que se homologan como juventud, como fiesta y como pueblo dentro del mundo civilizado en tiempos modernos.

En general, indica Álvarez (2011, p. 53), los amazonistas mencionan que la metamorfosis en estos pueblos pasa por imitar al otro sin dejar de ser uno mismo; afirmación discutible envuelta en una idea esencialista que no podemos sostener en el caso huaorani a la vista de su acelerado proceso de cambio. Difícil hablar de ellos mismos sin considerar las distancias intergeneracionales existentes, y la proximidad e incluso fusión existente con los otros.

\section{Conclusiones}

De acuerdo con la metáfora del contenedor, el cuerpo sustantiva las maneras de ser y estar en el mundo en base a la experiencia acumulada en el espacio y el tiempo; el habitus (Bourdieu, 1980; Viveiros de Castro, 1996) por el que cada persona y pueblo se distingue.

Inserto en las relaciones sociales y vinculado a la sustancia espiritual en la noción de persona, el cuerpo huaorani expresa con las transformaciones producidas en los últimos 60 años, el acelerado proceso de cambio socio cultural experimentado desde el momento del contacto.

El cuerpo guerrero evoca el tiempo en el que, pese a vivir en continua amenaza por las fuerzas depredadoras que les acechan (Rival, 2015, p. 285), eran los dominadores de la selva, como el jaguar en el que se transforman tras la muerte. Comprometidos con su libertad e independencia, se desarrolla un cuerpo esencialmente instrumental para lo básico: conseguir sustento y conservar la vida; colocado de manera permanente en un doble escenario: como matador-cazador y como presa.

El cuerpo cazador-recolector es el que queda con el inicio del proceso «civilizador». Las relaciones interculturales e interérnicas exige renunciar a lo que la sociedad dominante considera inapropiado, en este caso la guerra, aunque la renuncia no sea total. Comienza aquí también el proceso de «transfiguración étnica» (Riveiro, 1996), en cuanto que su pasado aislamiento y rechazo al mestizaje, se ve forzado progresivamente a disolver sus peculiaridades étnicas en un arquetipo indígena mayor como el Huao-Quichua. Cuerpo sin embargo, que aún con los cambios, no deja de estar amenazado y sigue percibiéndose como presa ${ }^{11}$.

El cuerpo deportico, por su parte, refleja la quiebra con la experiencia de sus mayores y antepasados. Conecta con los nuevos tiempos y posee una orientación especialmente relacional y recreativa, en la que el disfrute por el movimiento lúdico y las relaciones sociales son factores predominantes. Cuerpo además expresivo, por el que se muestra a través de su segunda piel (tatuada o labrada) y demás aditamentos (vestuario, peinados, etc.) una confusa identidad. Con todo ello, la aparente homologación a la juventud del siglo XXI, trae también consigo nuevos problemas que, como el suicidio $^{12}$, hace que sigan representándose como presa.

La intensidad de las presiones externas y del choque cultural, ha propiciado una enorme distancia intergeneracional. Los jóvenes, en general, no se muestran interesados en aprender, ni siquiera conocer, muchas de las costumbres de sus mayores; y los piquenanis no reconocen casi nada positivo de la juventud. Los cuerpos indolentes y aguerridos de unos ni siquiera desean ser recordados por los otros, al estar asociados al primitivismo y la barbarie; y los cuerpos de estos otros son observados con desprecio por los primeros al ser considerados blandos y débiles. La falta de comprensión de esos cuerpos denota una recíproca falta de miras, que dificulta el futuro común.

Conscientes de la necesidad de un mutuo reconocimiento entre jóvenes y mayores para afrontar los nuevos tiempos, el proyecto de diálogo intergeneracional propuesto desde el contexto educativo, abre esperanzas a que los jóvenes se interesen, conozcan, entiendan y valoren el pasado y tradiciones de su pueblo, al tiempo que los mayores comprendan y respeten los anhelos de la juventud. Importante reto de un proyecto recién iniciado, cuyos resultados están por ver, y en el que, para comprobar sus avances, habrá que estar atentos a cómo han llegado a entender sus respectivos cuerpos, en diálogo.

\section{Referencias}

Aguila, C., \& López Vargas, J. J. (2019). Cuerpo, corporeidad y educación: una mirada reflexiva desde la Educación Física. Retos: nuevas tendencias en educación física, deporte y recreación, 35, 213-421.

Álvarez, K. (2011). Prácticas funerarias en los waorani. Quito: FLACSO-ABYA

Arrayás, M. J., Tornero, I., \& Díaz, M. S. (2018). Percepción de la imagen corporal de los adolescentes de Huelva atendiendo al género y a la edad. Retos: nuevas tendencias en educación física, deporte y recreación, 34, 40-43.

Baudrillard, J. (1974). La société de consommation. Ses mythes, ses structures. París: Gallimard.

Birdwistell, R. M. (1952). Kinesics and context: essays on body motion communication. New York: Ballantine.

Bourdieu, P. (1978). Sport and Social Class. Social Science Information, 17 (6), 819-840.

Bourdieu, P. (1980). Le sens practique. Paris: Les Editions de Minuit. Brohm, J.M. (1982). Sociología política del deporte. México: F.C.E.

Cabodevilla, M.A. (1994). Los Huaorani en la historia de los pueblos del Oriente. Coca: CICAME.

Cabodevilla, M.A. y Aguirre, M. (2013). Una tragedia oculta. Quito: CICAME / Fundación Alejandro Labaka.

Csordas (1990). Embodiment as aparadigm for Anthropologist. Ethos, 18, 5-47,

De la Torre, M. J., Ruíz-Ariza, A., López, S., \& Martínez López, E. J. (2018). La parentalidad transformacional se relaciona positivamente con el autoconcepto físico de jóvenes adolescentes. Retos: nuevas tendencias en educación física, deporte y recreación, 34, 3-7

Douglas, M. (1978). Símbolos naturales. Madrid: Alianza Universidad.

Esteban, M.L. (2004). Antropología del cuerpo. Género, itinerarios corporales, identidad y cambio. Barcelona: Ediciones Bellaterra.

Foucault, M. (1984). Vigilar y castigar. Nacimiento de la prisión. 
México: Siglo XXI.

Geertz, C. (1987) [1973]. La interpretación de las culturas. Barcelona: Gedisa.

Godelier, M. (1986). La producción de grandes hombres. Poder y dominación entre los Baruya de Nueva Guinea. Madrid: Akal.

Goffman, E. (1987). La presentación de la persona en la vida cotidiana. Buenos Aires: Amorrortu.

Goldáraz, J. M. (2017). La selva rota. Crónicas desde el río Napo. Quito: Abya Yala / CICAME.

Hall, T.H. (1972). La dimensión oculta. Madrid: Siglo XXI.

Knapp, M.L. (1985). La comunicación no verbal. El cuerpo y el entorno. Barcelona: Paidós.

Le Bretón, D. (2002) [1990]. Antropología del cuerpo y la modernidad. Buenos Aires: Ediciones Nueva Vision.

Mauss, M. (1971). Sociología y Antropología. Madrid: Tecnos.

Merleau-Ponty, M. (1966). Signos. Barcelona: Seix Barral.

Merleau-Ponty, M. (1985). Fenomenología de la percepción. Barcelona: Planeta Agostini

Muñiz, E. (ed.) (2008). Registros corporales. La historia cultural del cuerpo humano. México DF: Universidad Autónoma Metropolitana / CONACIT.

Rival, L. (1996). Hijos del Sol, padres del jaguar: Los huaorani de ayer y de hoy. Quito: Abya Yala.

Rival, L. (2015). Transformaciones huaoranis. Frontera, cultura y tension. Quito: Universidad Andina Simón Bolivar / Latin American Centre / Abya Yala.

Rivas, A. \& Lara, R. (2001). Conservación y petróleo en la Amazonía Ecuatoriana. Un acercamiento al caso waorani. Quito: AcoCiencia / Abya-Yala.

Riveiro, D. (1996). Os indios e a civilizacao. A integracao das populaciones indígenas no Brasil moderno. Sao Paulo: Editora Schwarz.

Robarchek, C. y Robarchek, C. (1998). Waorani; the contexts of violence and war. Orlando: Harcourt Brace.

Salinas, L. (1994). La construcción social del cuerpo. REIS, 68, 8596.

Velasco H. M. (2007). Cuerpo y espacio. Símbolos y metáforas, representación y expresividad de las culturas. Madrid: Editorial Universitaria Ramón Areces.

Viveiros de Castro, E. (1996). Os Pronomes Cosmologicos e o Perspectivismo Ameríndio. Mana, 2 (29), 115-144.

Wilson, J. y Bayón, M. (2017). La selva de los elefantes blancos. Megaproyectos y extractivismos en la Amazonía ecuatoriana. Quito: Abya Yala / Instituto de Estudios Ecológicos del Tercer Mundo.

Yost, J. (1991). Los Waodani: un pueblo de la selva. En Ecuador al estilo de la sombra de los Volcanes. M. Acosta-Solis, Ed. Quito: Ediciones Mundi Libri.

Zurita, M.G. (2017). Cultivando las plantas y la sociedad waorani. Boletim do Museu Paraense Emílio Goeldi. Ciências Humanas, 12 (2), 495-516.

\section{(Footnotes)}

${ }^{1}$ De manera puntual realizamos incursiones a comunidades de su entorno próximo, tales como Awencado, Kenaweno, Nemompare, Kiwaro o Tzapino, a fin de entrevistar a determinados piquenanis (personas de avanzada edad).

${ }^{2}$ De los 150 estudiantes (que en 2018 estaban escolarizados en la Unidad Educativa del Milenio, 85 varones $(56.7 \%)$ y 65 mujeres (43.3\%), mantuvimos diversas sesiones en el aula con $8^{\circ}, 9^{\circ}, 10^{\circ}$ de EGB, $1^{\circ}, 2^{\circ}$ y $3^{\circ}$ de Bachiller, por separado, jóvenes de entre 12 y 18 años, aunque algunos de ellos mayores de esa edad, a fin de conocer sus opiniones y generar debate sobre diversas cuestiones; así como para saber, a través del dibujo, la imagen que tienen de un supuesto mundo ideal donde desearan vivir. En total nos reunimos y dialogamos en clase con 84 alumnos (46 varones y 38 mujeres) y obtuvimos 64 dibujos individuales (de 38 varones y 26 mujeres).

${ }^{3}$ Según Rivas \& Lara (2001, p. 48), lo fue en 1978.

${ }^{4} \mathrm{La}$ abundancia natural de la selva se piensa que es resultado de las actividades de subsistencia de sus antepas ados por el lugar (Rival, 2015, p. 255).

${ }^{5}$ Los Tagaeri son Huaorani que a finales de los años 50 siguieron a Taga, su líder, decidiendo continuar aislados y no aceptar el contacto como hicieron el resto de familias.

${ }^{6}$ Entre tales disfunciones figuran las siguientes: falta de energía eléctrica por no disponer de combustible; equipos informáticos inutilizados por falta de internet; cortes continuos en el agua por deficiente canalización; inutilidad de los laboratorios de Física, Química, Informática y Ciencias Naturales; cierre permanente de una Biblioteca mal confecciona$\mathrm{da}$; internado sin responsable; raciones de comida insuficientes; falta de profesorado para completar el currículum de asignaturas; falta de personal administrativo. Todo ello sin entrar en la competencia y actitud del profesorado, que en algunos casos sería discutible. Frente a los numerosos problemas denunciados por la dirección del Centro, la Delegación Provincial y el Ministerio de Educación hacen oídos sordos.

${ }^{7}$ La empresa Cantarida que realizó la obra a través de la institución estatal Ecuador Estratégico, dejó una deuda impagada de varias mensualidades a unas 50 personas, que aún están pendiente de cobro, lo que generó también malestar en la población.

${ }^{8}$ Según Álvarez (2011, p. 232), los cuerpos y espíritus huaorani son parcialmente independientes.Mientras los cuerpos son hechos sin misterio, fruto de la unión de la sangre femenina y el semen masculino, «las almas proceden de fuerzas sobrenaturales, y se insertan secretamente en los fetos durante el embarazo». Sin embargo, de acuerdo a la creencia, contaba José Miguel Goldáraz (conversación personal, 28/ 10/2018), el espíritu del enemigo quedaba atrapado en su cuerpo por las lanzas que le clavaban, asegurándose así que no tomen represalias desde el más allá. Sacar las lanzas del cadáver, como hizo el propio Goldáraz al encontrar a Monseñor Labaca asesinado junto a la maloca tagaeri, supone liberar ese espíritu, y arriesgarse a ser también lanceado.

${ }^{9}$ Solo cuando se participa en algún campeonato con trofeo, o cuando hay alguna apuesta en juego, el resultado adquiere importancia.

${ }^{10}$ El huaorani G. Nenquimo contaba que también se tatúan las zonas íntimas, y ha llegado a ver un arete en la lengua.

${ }^{11}$ Presa no tanto por el potencial y permanente estado de guerra del pasado, sino por la amenaza chamánica y las influencias dañinas de los nuevos agentes externos.

${ }^{12}$ El suicidio adolescente constituye un serio problema en la actualidad. En Toñampari y su entorno próximo registramos un total de 11 suicidios consumados y10 intentos frustrados desde 1996 a 2018, seis de los cuales (consumados), con una media de edad de 18 años, tuvieron lugar en el último quinquenio. En dicho periodo alcanza una tasa de 265 por cada 100.000 habitantes, convirtiéndose en una auténtica epidemia. 